\title{
VWF/ADAMTS13 ratio as a potential biomarker for early detection of hepatocellular carcinoma
}

Hiroaki Takaya ${ }^{1}$, Tadashi Namisaki ${ }^{*}$ (D), Mitsuteru Kitade ${ }^{1}$, Kosuke Kaji ${ }^{1}$, Keisuke Nakanishi ${ }^{1}$, Yuki Tsuji $^{1}$, Naotaka Shimozato', Kei Moriya', Kenichiro Seki ${ }^{1}$, Yasuhiko Sawada', Soichiro Saikawa', Shinya Sato', Hideto Kawaratani ${ }^{1}$, Takemi Akahane ${ }^{1}$, Ryuichi Noguchi ${ }^{1}$, Masanori Matsumoto ${ }^{2}$ and Hitoshi Yoshiji ${ }^{1}$

\begin{abstract}
Background: To investigate the von Willebrand factor to ADAMTS13 ratio as a potential biomarker for early detection of hepatocellular carcinoma (HCC) in cirrhosis.

Methods: Serum levels of alpha-fetoprotein, des- $\gamma$-carboxy prothrombin, Lens culinaris agglutinin-reactive fraction of alpha-fetoprotein (alpha-fetoprotein-L3\%), vascular endothelial growth factor, and vascular endothelial growth factor receptor-2, as well as the plasma levels of von Willebrand factor antigen (von Willebrand factor: Ag) and ADAMTS13 activity (ADAMTS13:AC), were evaluated in 41 cirrhotic patients with HCC undergoing radiofrequency ablation and in 20 cirrhotic patients without HCC. The diagnostic accuracy of each biomarker was evaluated using the receiver operating characteristic curve analysis.

Results: The von Willebrand factor: Ag and von Willebrand factor: Ag/ADAMTS13:AC ratios were significantly higher in cirrhotic patients with HCC than in those without HCC ( $p<0.05$ and $p<0.01$, respectively), whereas ADAMTS13:AC was significantly lower in those with HCC than those without HCC ( $p<0.05)$. However, no relationship was observed between the von Willebrand factor: Ag/ADAMTS13:AC ratio and serum tumor markers such as alpha-fetoprotein, des- $\gamma$ carboxy prothrombin, and alpha-fetoprotein-L3\%. Multivariate regression analysis identified von Willebrand factor: Ag/ ADAMTS13:AC ratio and alpha-fetoprotein-L3\% as significant factors of HCC development. Receiver operating characteristic analysis showed that the von Willebrand factor: Ag/ADAMTS13:AC ratio and alpha-fetoprotein-L3\% had a better performance than alpha-fetoprotein, des- $\gamma$-carboxy prothrombin, alpha-fetoprotein-L3\%, vascular endothelial growth factor, and vascular endothelial growth factor receptor-2, von Willebrand factor: Ag, and ADAMTS13:AC. The von Willebrand factor: Ag/ADAMTS13:AC ratio was exclusively correlated with tumor volume and stage as well as serum vascular endothelial growth factor levels.
\end{abstract}

Conclusions: The von Willebrand factor: Ag/ADAMTS13:AC ratio can potentially serve as a novel biomarker for early diagnosis of HCC in cirrhotic patients.

Keywords: ADAMTS13, WWF, Biomarker, HCC, Early diagnosis

\footnotetext{
* Correspondence: tadashin@naramed-u.ac.jp

${ }^{1}$ Third Department of Internal Medicine, Nara Medical University, Shijo-cho

840, Kashihara, Nara 634-8522, Japan

Full list of author information is available at the end of the article
}

(c) The Author(s). 2019 Open Access This article is distributed under the terms of the Creative Commons Attribution 4.0 International License (http://creativecommons.org/licenses/by/4.0/), which permits unrestricted use, distribution, and reproduction in any medium, provided you give appropriate credit to the original author(s) and the source, provide a link to the Creative Commons license, and indicate if changes were made. The Creative Commons Public Domain Dedication waiver (http://creativecommons.org/publicdomain/zero/1.0/) applies to the data made available in this article, unless otherwise stated. 


\section{Background}

Hepatocellular carcinoma (HCC) represents the sixth most common cancer worldwide [1] and is the second leading cause of cancer-related death [2, 3]. Japan has one of the highest incidences of HCC in the world [1, 4]. Therefore, the diagnosis of very early stage HCC (defined as a single nodule sized $\leq 2 \mathrm{~cm}$ ) is a vital prerequisite for optimizing the treatment outcomes; however, until date, it remains challenging. The professional society guidelines from the European Association for the Study of the Liver [5] and American Association for the Study of Liver Diseases [6] encourage surveillance using ultrasonography at every 6 months in patients with cirrhosis. However, they do not agree with the addition of alpha fetoprotein (AFP) as an adjunct surveillance test. The Japan Society of Hepatology Consensus-Based Clinical Practice Guidelines for the Management of HCC recommends the use of three tumor markers AFP, des- $\gamma$-carboxy prothrombin (DCP), and alpha-fetoprotein-L3\% (AFP-L3) in combination with ultrasonography [7]. This approach has contributed to increase the detection of small HCCs in Japan in comparison to that in Europe and America. Furthermore, AFP-L3\% has been identified as a biomarker for the early detection of HCC due to its higher specificity in comparison with that of AFP [8]. The combination use of AFP-L3 and DCP plus ultrasonography achieved a sensitivity of approximately $85 \%$ and a specificity of approximately $95 \%$ [9], whereas AFP yielded no additional benefit to ultrasonography [10]. However, AFP-L3 is not routinely used outside of Japan. Therefore, universally available biological markers for the early diagnosis of HCC are urgently needed to improve the survival rate among patients with cirrhosis.

The tumor microenvironment, notably including the surrounding blood vessels; the hepatic non-parenchymal cells, such as Kupffer cells, hepatic stellate cells (HSCs), liver sinusoidal endothelial cells; and the diverse types of lymphocytes, plays a crucial role in tumor initiation and progression in HCC [11]. A disintegrin-like and metalloproteinase with thrombospondin type-1 motifs 13 (ADAMTS13) is predominantly produced in HSCs and cleaves newly secreted, unusually large von Willebrand factor (VWF) multimers (UL-VWFM) on the endothelial surface under high shear stress [12-14]. An imbalance between ADAMTS13 activity and UL-VWFM, formed by endothelial cell (EC) secretion of VWF from the endothelial surface, triggers thrombosis by inducing platelet adhesion and aggregation [15]. This marked imbalance between VWF antigen (VWF:Ag) and ADAMTS13 activity (ADAMTS13:AC) is related closely to impaired hepatic functional reserve in cirrhotic patients $[16,17]$. The components of the coagulation cascade regulate various steps in tumor initiation, progression, and metastasis [18, 19]; therefore, coagulation-related factors could be molecular targets for the diagnosis of patients with HCC. The aim of this study was to investigate the VWF and ADAMTS13 as potential biomarkers for the early detection of $\mathrm{HCC}$ in cirrhotic patients.

\section{Methods \\ Patients}

A retrospective review of medical records was performed for 61 consecutive patients aged $\geq 20$ years with cirrhosis, of whom 41 (67.2\%) developed HCC and visited the Nara Medical University, Kashihara, Nara, Japan between April and November 2016. Patients with initial hypervascular HCCs who were diagnosed using dynamic contrast-enhanced CT (DCE-CT), DCE-MRI, or DCEultrasound (DCE-US) were enrolled in the present study. Percutaneous radio frequency ablation (RFA) was performed for all patients according to the Japan Society of Hepatology Consensus-Based Clinical Practice Guidelines for HCC management [20]. All patients underwent blood examination for AFP, DCP, and AFP-L3\% before the RFA procedure. Patients with infection, thrombosis, ascites, hepatic encephalopathy, or uncontrolled gastroesophageal varices were excluded. Patients who received anticoagulants were also excluded. Written consent was obtained from all patients who agreed to participate in the study when they were admitted to hospital and treated with RFA. The local ethics committee of Nara Medical University approved this study, and the study was performed in accordance with the ethical standards established in the Declaration of Helsinki. Informed consent was obtained from all the participants.

\section{Measurement of the three tumor markers}

Blood samples were obtained from cirrhotic patients with HCC prior to RFA. The serum AFP level was determined by enzyme-linked immunosorbent assay using a commercially available kit (ELISA-AFP; International Reagents, Kobe, Japan) [21, 22]. The serum DCP level was determined by sensitive enzyme immunoassay (Eitest PIVKA-II kit; Eisai Laboratory, Tokyo, Japan), according to the manufacturer's instructions [23, 24]. The serum AFP-L3 levels were measured using lectin affinity electrophoresis coupled with antibody affinity blotting (AFP Differentiation Kit L; Wako Pure Chemical Industries, Ltd., Osaka, Japan) and were finally expressed as a percent of AFP-L3 (AFP-L3 level/total AFP level $\times$ 100) [25-27] .

\section{Measurement of the serum vascular endothelial growth factor (VEGF) and VEGF receptor-2 (VEGFR2) levels}

Serum VEGF and VEGFR2 levels were determined using commercially available ELISA kits (Quantikine Human VEGF Immunoassay and Quantikine Human VEGF R2 
Immunoassay; R\&D Systems, Minneapolis, MN, USA) according to the manufacturer's instructions $[28,29]$.

\section{Determination of plasma levels of VWF antigen and ADAMTS13 activity}

Blood samples were obtained from patients at the time of admission, during their hospital stay, or during regular outpatient treatment and were stored in plastic tubes containing $0.38 \%$ volume of sodium citrate. Platelet-poor plasma was prepared by centrifuging at $3000 \times \mathrm{g}$ at $4{ }^{\circ} \mathrm{C}$ for $15 \mathrm{~min}$ and was stored in aliquots at $-80^{\circ} \mathrm{C}$ until analysis. The sensitive chromogenic ELISA (Kainos Laboratories Inc., Tokyo, Japan) was used to determine Plasma ADAMTS13:AC [30]. The normal value for ADAMTS13:AC was $99 \pm 22 \%$. Plasma VWF:Ag was measured by sandwich ELISA using a rabbit anti-human VWF polyclonal antiserum (Dako, Glostrup, Denmark). The normal value for VWF:Ag is 102\% $\pm 33 \%$ [31].

\section{Statistical analysis}

The Mann-Whitney $U$ test was used to analyze the differences between cirrhotic patients with and without HCC. The Spearman's rank test was used to calculate correlations. Fisher's exact test was used to analyze categorical data. The data were expressed as mean \pm standard deviation. Univariate analysis and multivariate logistic regression with stepwise variable selection were used to determine the factors associated with early detection of HCC. The diagnostic accuracy of biomarkers for the early diagnosis of HCC [sensitivity, specificity and area under the curve (AUC)] was determined using the area under the receiver operating characteristic (ROC) curve $[32,33]$. A two-tailed $p$ value of less than 0.05 was considered significant. All analyses were carried out using EZR (Saitama Medical Center, Jichi Medical University), a graphical user interface for $R$ (The $R$ Foundation for Statistical Computing, version 2.13.0). Specifically, EZR is a modified version of $\mathrm{R}$ commander (version 1.6-3) that includes statistical functions that are frequently used in biostatistics [34].

\section{Results}

\section{Clinical characteristics of the patients}

Table 1 summarizes the clinical characteristics of the 61 cirrhotic patients with and without HCC. The study population had a median age of 74 years and comprised 42 men and 19 women. The causes of liver disease were hepatitis $\mathrm{C}$ virus $(\mathrm{HCV})(n=28)$, hepatitis $\mathrm{B}$ virus $(\mathrm{HBV})$ $(n=16)$, alcohol abuse $(n=8)$, non-alcoholic steatohepatitis $(n=6)$, and autoimmune hepatitis $(n=3)$. The median age of patients who developed HCC was 78 years. The median tumor size and volume were $1.6 \mathrm{~cm}$ and $4.0 \mathrm{~cm}^{3}$, respectively. The numbers of stage 1,2 , and 3 cases were 15, 19, and 7, respectively. The median serum aspartate aminotransferase and alanine aminotransferase levels were $30 \mathrm{IU} / \mathrm{L}$ and $27 \mathrm{IU} / \mathrm{L}$, respectively.

Table 1 Baseline characteristics of cirrhotic patients with and without HCC

\begin{tabular}{|c|c|c|c|c|}
\hline Variable & Total $(n=61)$ & Patients with HCC $(n=41)$ & Patients without HCC $(n=20)$ & $P$ value \\
\hline Age (years) & $74(67-79)$ & $78(67-79)$ & $72(64-76)$ & 0.19 \\
\hline Sex (male/female) & $42 / 19$ & $32 / 9$ & $10 / 10$ & 0.04 \\
\hline HCV/HBV/Alcohol/NASH/AlH & $28 / 16 / 8 / 6 / 3$ & $17 / 11 / 6 / 6 / 1$ & $11 / 5 / 2 / 0 / 2$ & 0.26 \\
\hline Albumin (g/dL) & $4.1(3.6-4.4)$ & $3.9(3.4-4.1)$ & $4.4(4.2-4.6)$ & 0.000004 \\
\hline Total bilirubin (mg/dL) & $0.9(0.7-1.2)$ & $0.9(0.7-1.2)$ & $0.85(0.8-1.2)$ & 0.88 \\
\hline Aspartate aminotransferase (IU/L) & $30(22-41)$ & $30(21-47)$ & $29.5(26-34)$ & 0.68 \\
\hline Alanine aminotransferase (IU/L) & $27(19-47)$ & $33(21-47)$ & $22(16-36)$ & 0.12 \\
\hline alkaline phosphatase (IU/L) & $315(233-432)$ & $315(237-427)$ & $314(230-483)$ & 0.93 \\
\hline Y-glutamyl transpeptidase (IU/L) & $33(24-56)$ & $32(24-82)$ & $34(23-45)$ & 0.58 \\
\hline Prothrombin time (\%) & $78(69-87)$ & $75(70-84)$ & $81(75-85)$ & 0.21 \\
\hline Child-Pugh score & $5.0(5-6)$ & $5.0(5-6)$ & $5.0(5-5)$ & 0.058 \\
\hline Platelet count $\left(\times 10^{4} / \mu \mathrm{L}\right)$ & $11.9(9.0-14.8)$ & $11.9(9.1-15.4)$ & $11.2(9.0-13.0)$ & 0.52 \\
\hline Tumor size $(\mathrm{cm})$ & & $1.6(1.2-2.2)$ & & \\
\hline Tumor volume $\left(\mathrm{cm}^{3}\right)$ & & $4.0(1.7-6.1)$ & & \\
\hline UICC TNM stage (stage 1/stage 2/stage 3 ) & & $15 / 19 / 7$ & & \\
\hline GALAD model (Score, Probability) & $1.8(0.7-3.2), 85(66-96)$ & $2.4(1.5-3.4), 92(81-98)$ & $0.7(-1.1-1.1), 67(27-75)$ & $0.00056,0.00068$ \\
\hline
\end{tabular}

Data are expressed as median (Inter Quartile Range)

$P$-values represent comparisons between cirrhotic patients with and without HCC

$H C C$ hepatocelullar carcinoma, $H C V$ hepatitis $C$ virus, $H B V$ hepatitis $B$ virus

NASH non-alcoholic steatohepatitis, AlH autoimmune hepatitis

TMN tumor/node/metastasis 
There were no significant differences between cirrhotic patients with and without HCC in all the characteristics, except for sex and the serum albumin level.

\section{Differences between patients with and without HCC in} tumor markers, GALAD score, angiogenic factors and procoagulation markers

We compared the tumor markers, angiogenic factors, and pro-coagulation markers between cirrhotic patients with and without HCC. The AFP-L3\%, GALAD score, VEGF, VEGFR-2 levels, as well as the VWF:Ag and VWF:Ag/ADAMTS13:AC ratio, were significantly higher in cirrhotic patients with $\mathrm{HCC}$ than in those without HCC $(p<0.01, p<0.01, p<0.05, p<0.01, p<0.05$, and $p<0.01$, respectively) (Fig. $1 \mathrm{c}, \mathrm{d}, \mathrm{e}, \mathrm{g}$, and $\mathrm{h}$ ). However, the ADAMTS13:AC was significantly lower in patients with $\mathrm{HCC}$ than in those without $\mathrm{HCC}(p<0.05)$ (Fig. 1 f). The AFP and DCP levels did not differ significantly between cirrhotic patients with and without HCC (Fig. 1 $a$ and $b)$.

\section{Correlation of the VWF:ag/ADAMTS13:AC ratio with} conventional tumor markers and platelet count

We examined the relationship between the VWF:Ag/ ADAMTS13:AC ratio and serum tumor markers, such as AFP, DCP, and AFP-L3\%. No relationship was observed between the VWF:Ag/ADAMTS13:AC ratio and any of the three tumor markers (Fig. 2 a, b, and c). The patients were categorized into two, according to the median cutoff VWF:Ag/ADAMTS13:AC ratio (low, $<5$ and high, $\geq 5$ ). The patients with a VWF:Ag/ADAMTS13:AC ratio $\geq 5$ had significantly higher platelet count, compared with those with a ratio $<5$ (Fig. 3). This indicated that the imbalance between VWF:Ag and ADAMTS13: AC may be linked to platelet hyperaggregability in cirrhotic patients with HCC.

\section{Diagnostic accuracy of the serum biomarkers for the early diagnosis of HCC}

Univariate and multivariate logistic regression analyses confirmed that the VWF:Ag/ADAMTS13:AC ratio and AFP-L3\% were significant factors associated with the early detection of HCC in cirrhotic patients (Table 2). ROC analysis showed that the area under the ROC curve of AFP, DCP, AFP-L3\%, VEGF, VEGFR2, ADAMTS13: $\mathrm{AC}, \mathrm{VWF}: \mathrm{Ag}$, and the VWF:Ag/ADAMTS13:AC ratio for the early diagnosis of $\mathrm{HCC}$ in patients with cirrhosis was $0.61,0.58,0.54,0.74,0.67,0.59,0.67,0.63$, and 0.73, respectively. The VWF:Ag/ADAMTS13:AC ratio and

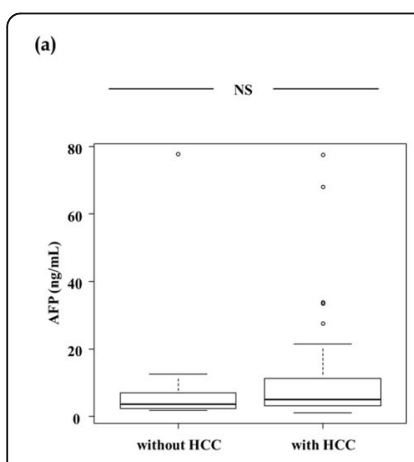

(e)

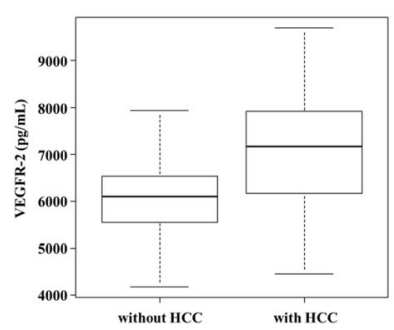

(b)

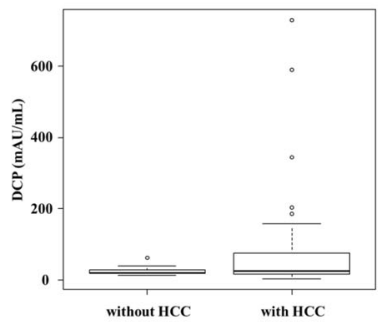

(f)

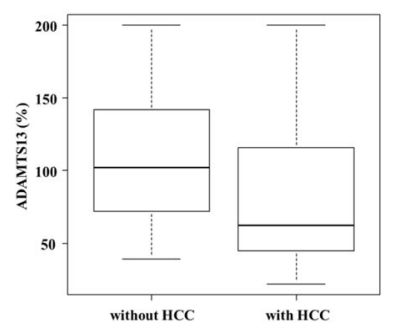

(c)

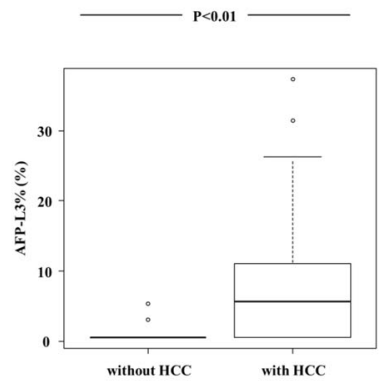

(g)

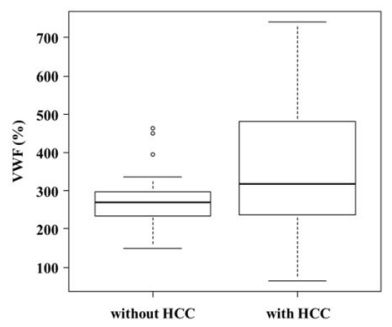

(d)

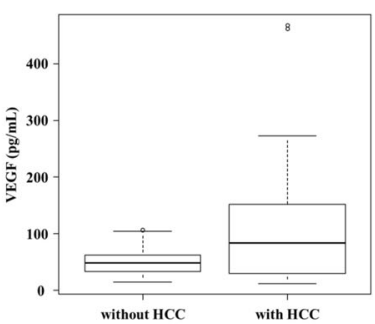

(h)

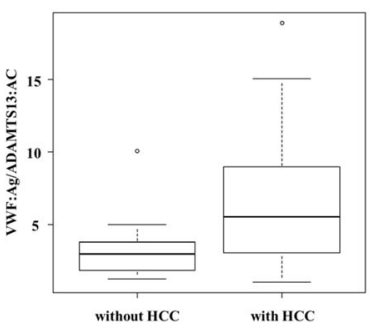

Fig. 1 Comparison of serum biomarkers between cirrhotic patients with HCC and those without HCC. The AFP (a) and DCP (b) levels did not differ significantly between cirrhotic patients with and without HCC. The AFP-L3\% (c), VEGF (d), VEGFR-2 (e) levels, as well as the WWF:Ag (g) and WWF:Ag/ ADAMTS13:AC ratio (h), were significantly higher in cirrhotic patients with HCC than in those without HCC. The ADAMTS13:AC (f) was significantly lower in patients with HCC than in those without HCC. Asterisks indicate statistically significant differences between the indicated experimental groups $(p<0.05, p<0.01)$. WW, von Willebrand factor; WF:Ag, WF antigen; ADAMTS13, a disintegrin-like and metalloproteinase with thrombospondin type 1 motifs 13; ADAMTS13:AC, ADAMTS13 activity; VEGF, vascular endothelial growth factor; VEGFR-2, VEGF receptor-2; AFP, alpha-fetoprotein; AFP-L3\%, Lens culinaris agglutinin-reactive AFP; DCP, des- $\gamma$-carboxy prothrombin; HCC: hepatocellular carcinoma; NS, not significant 

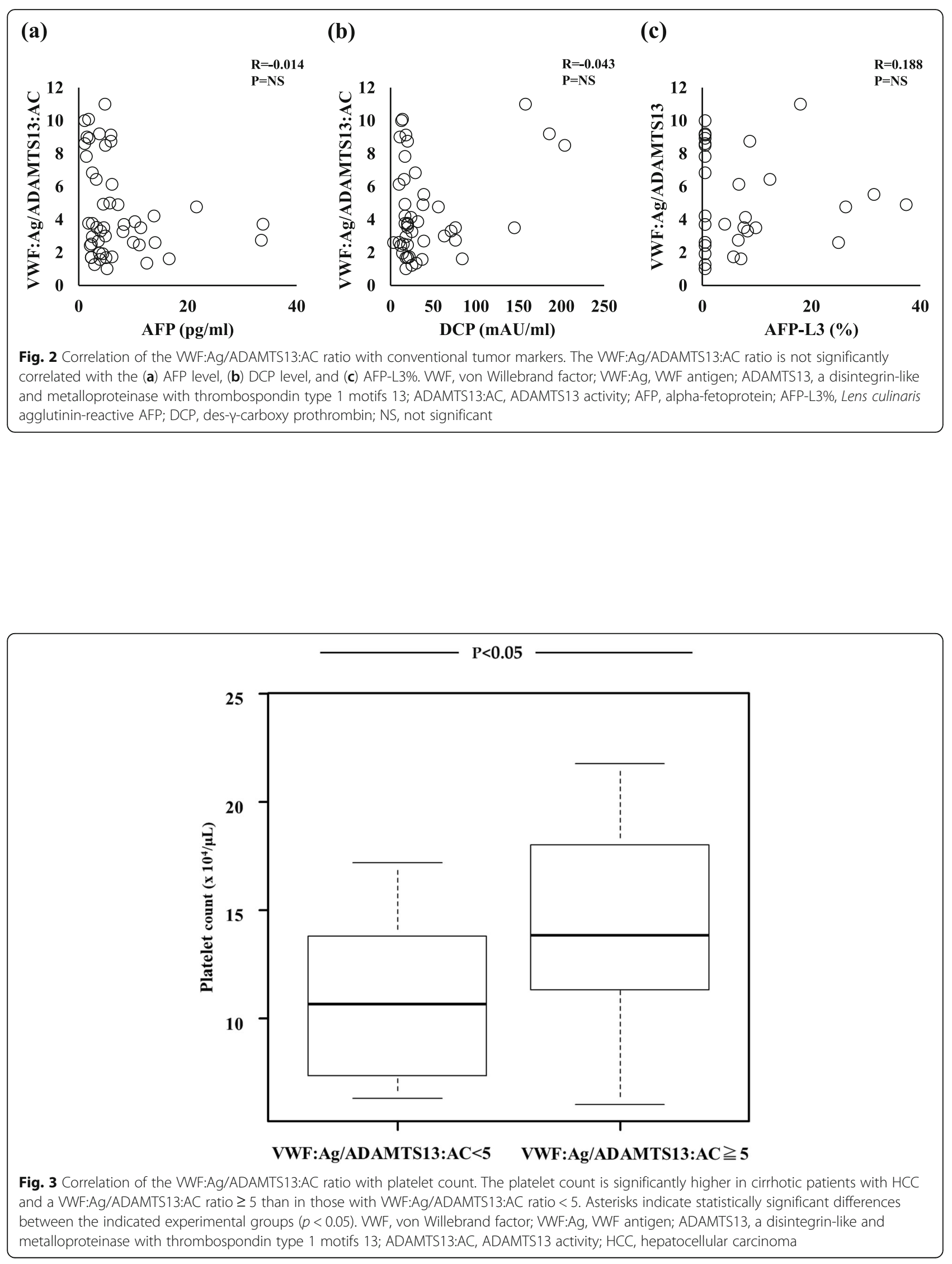
Table 2 The diagnostic accuracy of biomarkers for early detection of HCC

\begin{tabular}{lll}
\hline Variable & OR $(95 \% \mathrm{Cl})$ & $P$ value \\
\hline Unvariable analysis & & \\
AFP $>10 \mathrm{ng} / \mathrm{mL}$ & $1.01(0.98-1.05)$ & 0.49 \\
$\mathrm{DCP}>40 \mathrm{mAU} / \mathrm{mL}$ & $5.48(1.10-27.3)$ & 0.038 \\
AFP-L3\% $>5 \%$ & $15.9(1.89-134.0)$ & 0.011 \\
VEGF $>100 \mathrm{pg} / \mathrm{mL}$ & $7.06(1.39-35.9)$ & 0.019 \\
VEGFR2 $>6500 \mathrm{pg} / \mathrm{mL}$ & $2.46(0.796-7.63)$ & 0.12 \\
ADAMTS13:AC > 60\% & $0.31(0.0874-1.10)$ & 0.082 \\
WWF:Ag $>300 \%$ & $4.31(1.30-14.3)$ & 0.017 \\
WWF:Ag/ADAMTS13:AC > 5 & $8.95(1.82-44.0)$ & 0.007 \\
Multivariable analysis & & \\
AFP-L3\% $>5 \%$ & $19.5(1.78-214.0)$ & 0.015 \\
WWF:Ag/ADAMTS13:AC > 5 & $18.5(1.64-209.0)$ & 0.018 \\
\hline
\end{tabular}

HCC hepatocellular carcinoma, AFP alpha fetoprotein, DCP des- $\gamma$-carboxy prothrombin

AFP-L3\%, Lens culinaris agglutinin-reactive alpha-fetoprotein

VEGF, vascular endothelial growth factor; VEGFR-2, VEGF receptor-2

ADAMTS13, a disintegrin-like and metalloproteinase with thrombospondin type 1 motifs 13

VWF, von Willebrand factor; ADAMTS13:AC, ADAMTS13 activity

VWF:Ag, von Willebrand factor antigen; VWF:Ag/ADAMTS13:AC, ratio of

VWF:Ag to ADAMTS13:AC. Cl, confidence interval; $O R$, odds ratio

AFP-L3\% showed a better performance than AFP, DCP, VEGF, VEGFR2, ADAMTS13:AC, and VWF:Ag (Table. 3). The diagnostic accuracy of the VWF:Ag/ ADAMTS13:AC ratio (Cutoff value 5.5, sensitivity $51 \%$, specificity $95 \%$, and AUC 0.73) is comparable with that of AFP-L3\% (Cutoff value 5.7, sensitivity 54\%, specificity 93\%, and AUC 0.74) (Fig. 4).

Table 3 The receiver operating characteristic (ROC) curve of the biomarkers

\begin{tabular}{llll}
\hline Variable & Sensitivity & Specificity & AUC \\
\hline AFP & 0.68 & 0.55 & 0.61 \\
DCP & 0.46 & 0.85 & 0.58 \\
AFP-L3\% & 0.54 & 0.93 & 0.74 \\
VEGF & 0.47 & 1.00 & 0.67 \\
VEGFR2 & 0.59 & 0.58 & 0.59 \\
ADAMTS13:AC & 0.56 & 0.79 & 0.67 \\
WWF:Ag & 0.59 & 0.75 & 0.63 \\
WWF:Ag/ADAMTS13:AC & 0.51 & 0.95 & 0.73 \\
\hline AFP
\end{tabular}

AFP alpha fetoprotein, $D C P$ des- $\gamma$-carboxy prothrombin

AFP-L3\%, Lens culinaris agglutinin-reactive alpha-fetoprotein

VEGF vascular endothelial growth factor, VEGFR-2 VEGF receptor-2

ADAMTS13 a disintegrin-like and metalloproteinase with thrombospondin type 1 motifs 13

VWF, von Willebrand factor; ADAMTS13:AC, ADAMTS13 activity

VWF:Ag, von Willebrand factor antigen; VWF:Ag/ADAMTS13:AC, ratio of VWF:Ag to ADAMTS13:AC

$A U C$, area under the curve

\section{Correlation of the tumor volume and stage with the VWF:ag/ADAMTS13:AC ratio and AFP-L3\%}

We determined the relationship of tumor volume and stage with the VWF:Ag/ADAMTS13:AC ratio and AFPL3\%. Tumor volume and stage significantly correlated with the VWF:Ag/ADAMTS13:AC ratio $(p=0.0002$ and $p=0.046$, respectively) but not with the AFP-L3\% (Table 4).

\section{Correlation of serum VEGF levels with the VWF:ag/ ADAMTS13:AC ratio and AFP-L3\%}

Given that HCC is a highly vascularized tumor, angiogenesis is one of the main contributors to HCC development in which the VEGF signaling pathway plays a pivotal role. Therefore, we investigated whether there was a relationship between the serum VEGF level and the VWF:Ag/ADAMTS13:AC ratio or AFP-L3\%. The serum VEGF level was significantly correlated with the VWF:Ag/ADAMTS13:AC ratio $(p<0.05)$ (Fig. 5 a) but not with AFP-L3\% (Fig. 5 b).

\section{Discussion}

In recent years, several promising candidate biomarkers for the early detection of HCC have been identified; however, most of these have not been applied for clinical diagnosis due to their high cost and limited practicality in clinical practice $[35,36]$. Accordingly, there is a critical unmet medical need to identify novel specific biomarkers for the early detection of HCC. To the best of our knowledge, this was the first report demonstrating that the VWF:Ag/ADAMTS13:AC ratio could serve as a novel biomarker for the early diagnosis of HCC in cirrhotic patients. In the present study, the findings showed that imbalances in the ADAMTS13 enzymeVWF substrate were associated with HCC development. Moreover, ADAMTS13:AC was reduced in cirrhotic patients with HCC, compared with those without HCC. In contrast, Ikeda et al. revealed that plasma ADAMTS13: $\mathrm{AC}$ was higher in patients who developed HCC than in those who did not and that ADAMTS13:AC was an independent risk factor for HCC development [37]. The reason for this different result between the two studies remains unclear. However, one possible explanation is the differences in the progression and the underlying cause of chronic liver disease between the studies. All the patients in our study developed cirrhosis, whereas in the study by Ikeda et al., $43 \%$ of the patients had chronic hepatitis [37]. The patients in the present study included those with alcoholic hepatitis, non-alcoholic hepatitis, and autoimmune hepatitis, as well as those with HBV- and HCV-related cirrhosis; whereas only patients with HBVand HCV-related chronic hepatitis and cirrhosis were included in the study by Ikeda et al. [37]. Furthermore, cirrhotic patients frequently have hypercoagulability, resulting 


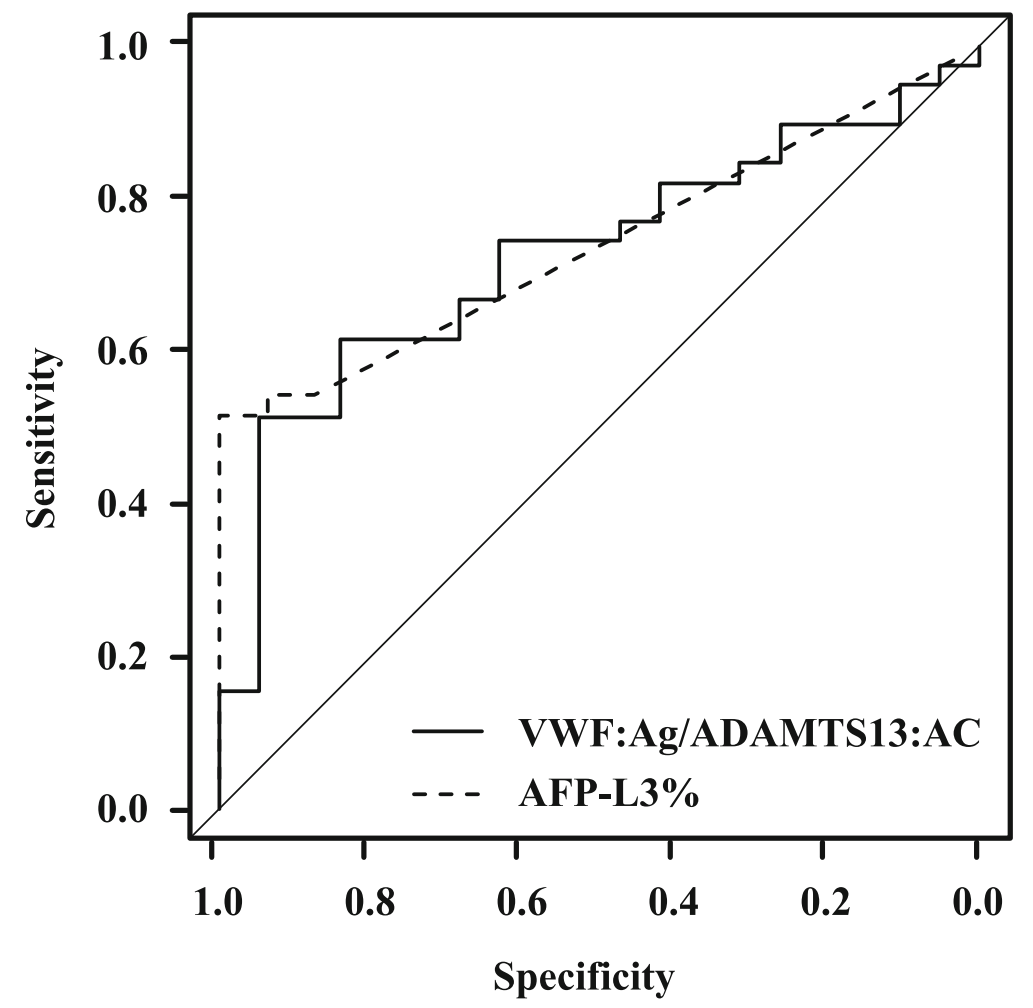

Fig. 4 Diagnostic accuracy of serum biomarkers for the early detection of HCC. The diagnostic accuracy of the WWF:Ag/ADAMTS13:AC ratio (Cutoff value 5.5, sensitivity 51\%, specificity 95\%, and AUC 0.73) is comparable with that of AFP-L3\% (Cutoff value 5.7, sensitivity 54\%, specificity 93\%, and AUC 0.74). WWF, von Willebrand factor; VWF:Ag, WWF antigen; ADAMTS13, a disintegrin-like and metalloproteinase with thrombospondin type 1 motifs 13; ADAMTS13:AC, ADAMTS13 activity; AUC, area under the curve; AFP-L3\%, Lens culinaris agglutinin-reactive alpha-fetoprotein; HCC, hepatocellular carcinoma

in markedly increased risk for thromboembolism [38, 39]. ADAMTS13 cleaves the VWF in plasma to generate smaller, less thrombogenic fragments. ADAMTS13:AC decreases with increasing severity of liver disease, leading the observed imbalance between the decreased ADAMTS13: $\mathrm{AC}$ and the increased VWF:Ag in cirrhotic patients [16, 17]. These results further supported the hypothesis that ADAMTS13 enzyme-VWF substrate imbalances could be

Table 4 Correlation of the tumor volume and stage with the WWF:Ag/ADAMTS13:AC ratio and AFP-L3\%

\begin{tabular}{lll}
\hline Variable & Correlation coefficients & $P$ value \\
\hline Tumor volume vs. WWF/ADAMTS13 & 0.58 & 0.0002 \\
Tumor stage vs. WWF/ADAMTS13 & 0.38 & 0.046 \\
Tumor volume vs. AFP-L3\% & 0.18 & 0.91 \\
Tumor stage vs. AFP-L3\% & 0.28 & 0.86
\end{tabular}

HCC, hepatocelullar carcinoma

ADAMTS13, a disintegrin-like and metalloproteinase with thrombospondin type 1 motifs 13

VWF, von Willebrand factor; ADAMTS13:AC, ADAMTS13 activity

VWF:Ag, von Willebrand factor antigen

AFP-L3\%, Lens culinaris agglutinin-reactive alpha-fetoprotein

VWF:Ag/ADAMTS13:AC, ratio of VWF:Ag to ADAMTS13:AC related with the hypercoagulability associated with HCC development in cirrhotic patients.

In addition, angiogenesis plays an important role in hepatocarcinogenesis in the early stages. The development of HCC is dependent on the formation of new blood vessels, in which the role of VEGF is critical [40]. The binding of the VWF to integrin av $\beta 3$ represses the VEGFR-2 activity and the downstream pro-angiogenic signaling pathways [41, 42]. However, in the current study, VWF:Ag were higher in cirrhotic patients with HCC than in those without HCC. Furthermore, Liu et al. demonstrated that VWF:Ag increased with the progression of chronic hepatitis to HCC [43]. Recently, we found that VWF:Ag increases during the development of HCC [44]. The biological function of VWF depends largely on the size of VWF multimers [45]. Large VWF multimers have been reported to be deficient in malignant diseases [46], indicating a decline in the VWF function. Moreover, the loss of large VWF multimers has been shown to be compensated by an increase in the VWF antigen levels [47]. In addition, ADAM is a fascinating family of secreted transmembrane proteins that function to regulate cell phenotypes through the effects on cell adhesion, migration, 

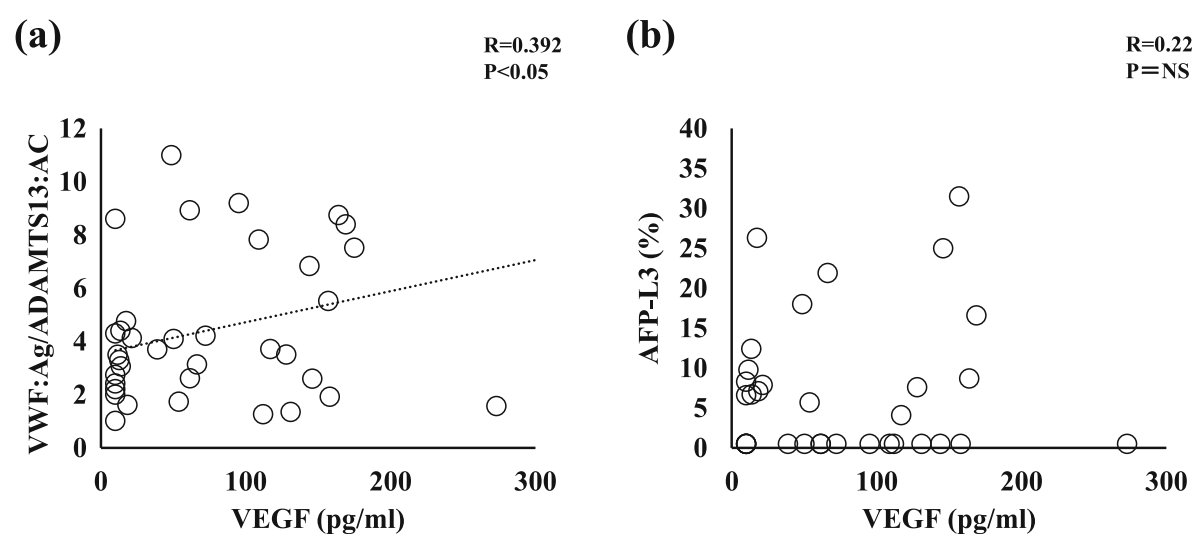

Fig. 5 Correlation of the serum VEGF levels with the WWF:Ag/ADAMTS13:AC ratio and AFP-L3\%. The serum VEGF level is significantly correlated with the WWF:Ag/ADAMTS13:AC ratio (a) but not with the AFP-L3\% levels (b). WWF, von Willebrand factor; VWF:Ag, WWF antigen; ADAMTS13, a disintegrin-like and metalloproteinase with thrombospondin type 1 motifs 13; ADAMTS13:AC, ADAMTS13 activity; VEGF, vascular endothelial growth factor; AFP-L3\%, Lens culinaris agglutinin-reactive alpha-fetoprotein

proteolysis, and signaling [48]. The levels of ADAM domain-containing protein 28 (ADAM 28) are upregulated in malignant tumors [49], and ADAM 28 derived from cancer cells cleaves and inactivates the pro-apoptotic endogenous agent VWF [50]. These findings suggested that a reduction in the function of VWF results in elevated VWF:Ag in HCC.

ADAMTS13 promotes VEGFR-2 phosphorylation, leading to enhanced VEGF expression and improved angiogenic activity of ECs [51]. In contrast, an in vitro study revealed that when VEGF expression was abundant, ADAMTS13 exerted its anti-angiogenic effects on human ECs [52]. Other studies indicated that VEGF levels progressively increased during the successive stages of hepatocarcinogenesis [40] and that elevated VEGF expression was linked with early-stage HCC [53]. $\mathrm{A}$ recent study by $\mathrm{Xu}$ et al. revealed the critical role of a balance in the ADAMTS13 enzyme-VWF substrate in regulating blood vessel formation [42]. These findings reiterate the potential role of the VWF:Ag/ ADAMTS13:AC ratio in HCC development, suggesting a potential new biomarker that may allow early detection of HCC.

The present study had several limitations, including the absence of clinicopathologic or prognostic data and the small sample size. Patients with liver cirrhosis sometimes develop thrombosis or inflammation, including portal thrombosis, bacterial overgrowth, and translocation. When the VWF:Ag/ADAMTS13:AC ratio is used as a biomarker for the early detection of HCC, thrombosis and inflammation might affect the value of the ratio. Only patients with hypervascular HCCs were analyzed in the present study; therefore, pathologically, early or hypovascular HCC should be examined in the future. Further studies need to be carried out to validate the findings of the present study.

\section{Conclusion}

The VWF:Ag/ADAMTS13:AC ratio probably contributes to HCC development identified small, early-stage, and AFP-negative HCC in cirrhotic patients. Although the use of either VWF:Ag or ADAMTS13:AC alone would be insufficient in aiding the early diagnosis of $\mathrm{HCC}$, the ratio of the two biomarkers can greatly increase the accuracy. The diagnostic accuracy of the VWF:Ag/ADAMTS13:AC ratio was comparable with that of AFP-L3\%; nonetheless, the VWF:Ag/ADAMTS13:AC ratio is a remarkably superior diagnostic biomarker of AFP-L3\% in terms of universality and objectivity and could serve as a potentially favorable biomarker for the early diagnosis of HCC in cirrhotic patients.

\section{Abbreviations}

ADAMTS13: a disintegrin-like and metalloproteinase with thrombospondin type 1 motifs 13; ADAMTS13:AC: ADAMTS13 activity; AFP: alpha-fetoprotein; AFP-L3\%: Lens culinaris agglutinin-reactive fraction of alpha-fetoprotein; AUC: area under the curve; $C$ : computed tomography; DCP: des-y-carboxy prothrombin; EC: endothelial cells; ELISA: enzyme-linked immunosorbent assay; HBV: hepatitis B virus; HCC: hepatocellular carcinoma; HCV: hepatitis C virus; HSC: hepatic stellate cells; JSH: Japan Society of Hepatology; LSEC: liver sinusoidal endothelial cells; MRI: magnetic resonance imaging; RFA: radio frequency ablation; SD: standard deviation; UL-WWFM: von Willebrand factor multimers; US: ultrasonography; VEGF: vascular endothelial growth factor; VEGFR-2: VEGF receptor-2; WWF: von Willebrand factor; WWF:Ag: WWF antigen

\section{Acknowledgments}

This work was completed with the help of Ms. Yoshie Nakai, the late Prof. Masahito Uemura and the former Prof. Hiroshi Fukui.

\section{Authors' contributions}

H. T, M. K, K. K, K. N, Y. T, N. S, K. M, K. S, Y. S, S. S1, S. S2, H. K, T. A, R. N, and M. M performed data analysis; H. T, T. N, and H. Y contributed to the writing of the manuscript. All authors have read and approved the manuscript.

\section{Funding}

There was no grant support for this work. 


\section{Availability of data and materials}

Raw data were generated at Nara Medical University Hospital. Derived data supporting the findings of this study are available from the corresponding author [T.N] on request.

\section{Ethics approval and consent to participate}

The study protocol was approved by the Ethics Committee of Nara Medical University (project number: 1453) and conformed to the ethical guidelines of the 1975 Declaration of Helsinki. All subjects gave informed consent for participation.

\section{Consent for publication}

Not Applicable

\section{Competing interests}

The authors declare that they have no conflict of interest.

\section{Author details}

${ }^{1}$ Third Department of Internal Medicine, Nara Medical University, Shijo-cho 840, Kashihara, Nara 634-8522, Japan. ${ }^{2}$ Department of Blood Transfusion Medicine, Nara Medical University, Kashihara, Nara 634-8522, Japan.

Received: 21 November 2018 Accepted: 20 September 2019 Published online: 21 October 2019

\section{References}

1. Zhu RX, Seto WK, Lai CL, Yuen MF. Epidemiology of hepatocellular carcinoma in the Asia-Pacific region. Gut Liver. 2016;10(3):332-9.

2. Kudo M, Hatano E, Ohkawa S, Fujii H, Masumoto A, Furuse J, Wada Y, Ishii H, Obi S, Kaneko S, et al. Ramucirumab as second-line treatment in patients with advanced hepatocellular carcinoma: Japanese subgroup analysis of the REACH trial. J Gastroenterol. 2017;52(4):494-503.

3. Llovet JM, Zucman-Rossi J, Pikarsky E, Sangro B, Schwartz M, Sherman M, Gores G. Hepatocellular carcinoma. Nat Rev Dis Primers. 2016;2:16018.

4. Shima T, Uto H, Ueki K, Kohgo Y, Yasui K, Nakamura N, Nakatou T, Takamura T, Kawata S, Notsumata K, et al. Hepatocellular carcinoma as a leading cause of cancer-related deaths in Japanese type 2 diabetes mellitus patients. J Gastroenterol. 2018.

5. European Association for the Study of the Liver. Electronic address eee, European Association for the Study of the L: EASL clinical practice guidelines: management of hepatocellular carcinoma. J Hepatol. 2018;69(1): 182-236.

6. Heimbach JK, Kulik LM, Finn RS, Sirlin CB, Abecassis MM, Roberts LR, Zhu AX, Murad MH, Marrero JA. AASLD guidelines for the treatment of hepatocellular carcinoma. Hepatology. 2018;67(1):358-80.

7. Toyoda H, Kumada T, Tada T, Sone Y, Kaneoka Y, Maeda A, Minami Y, Kudo $M$, Siegel AB, El-Khoueiry AB, Finn RS. Clinical practice guidelines for hepatocellular carcinoma differ between Japan, United States, and Europe. Liver Cancer. 2015;4(2):85-95.

8. Li D, Mallory T, Satomura S. AFP-L3: a new generation of tumor marker for hepatocellular carcinoma. Clin Chim Acta. 2001;313(1-2):15-9.

9. Gish RG. Early detection of hepatocellular carcinoma through surveillance using biomarkers. Gastroenterol Hepatol (N Y). 2014;10(2):121-3.

10. Singal A, Volk ML, Waljee A, Salgia R, Higgins P, Rogers MA, Marrero JA. Metaanalysis: surveillance with ultrasound for early-stage hepatocellular carcinoma in patients with cirrhosis. Aliment Pharmacol Ther. 2009;30(1):37-47.

11. Sulpice L, Desille M, Turlin B, Fautrel A, Boudjema K, Clément B, Coulouarn C. Gene expression profiling of the tumor microenvironment in human intrahepatic cholangiocarcinoma. Genomics Data. 2016;7:229-32.

12. Takaya H, Yoshiji H, Kawaratani H, Sakai K, Matsumoto M, Fujimura Y, Fukui $H$. Decreased activity of plasma ADAMTS13 are related to enhanced cytokinemia and endotoxemia in patients with acute liver failure. Biomed Rep. 2017;7(3):277-85.

13. Takaya H, Uemura M, Fujimura $Y$, Matsumoto M, Matsuyama T, Kato S, Morioka C, Ishizashi H, Hori Y, Fujimoto M, et al. ADAMTS13 activity may predict the cumulative survival of patients with liver cirrhosis in comparison with the child-Turcotte-Pugh score and the model for end-stage liver disease score. Hepatol Res. 2012;42(5):459-72.

14. Takaya H, Kawaratani H, Kubo T, Seki K, Sawada Y, Kaji K, Okura Y, Takeda K, Kitade M, Moriya K, et al. Platelet hyperaggregability is associated with decreased ADAMTS13 activity and enhanced endotoxemia in patients with acute cholangitis. Hepatol Res. 2018;48(3):E52-60.

15. Akyol O, Akyol S, Chen C-H. Update on ADAMTS13 and WWF in cardiovascular and hematological disorders. Clin Chim Acta. 2016;463:109-18.

16. Uemura M, Fujimura Y, Matsumoto M, Ishizashi H, Kato S, Matsuyama T, Isonishi A, Ishikawa M, Yagita M, Morioka C, et al. Comprehensive analysis of ADAMTS13 in patients with liver cirrhosis. Thromb Haemost. 2008;99(06):1019-29.

17. Uemura M, Fujimura $Y$, Ko S, Matsumoto M, Nakajima $Y$, Fukui $H$. Determination of ADAMTS13 and its clinical significance for ADAMTS13 supplementation therapy to improve the survival of patients with decompensated liver cirrhosis. International Journal of Hepatology. 2011; 2011:759047.

18. Nierodzik MLR, Kajumo F, Karpatkin S. Effect of Thrombin Treatment of Tumor Cells on Adhesion of Tumor Cells to Platelets \&lt;em\&gt;in Vitro\&lt;/ em\&gt; and Tumor Metastasis \&lt;em\&gt;in Vivo\&lt;/em\&gt. Cancer Res. 1992 52(12):3267

19. Snyder KM, Kessler CM. The pivotal role of thrombin in Cancer biology and tumorigenesis. Semin Thromb Hemost. 2008;34(08):734-41.

20. Kudo M, Matsui O, Izumi N, lijima H, Kadoya M, Imai Y, Okusaka T, Miyayama S, Tsuchiya K, Ueshima K, et al. JSH consensus-based clinical practice guidelines for the Management of Hepatocellular Carcinoma: 2014 update by the liver Cancer study Group of Japan. Liver Cancer. 2014;3(3-4):458-68.

21. Zhang A, Skog S, Wang S, Ke Y, Zhang Y, Li K, He E, Li N. A chemiluminescent protein microarray method for determining the Seroglycoid Fucosylation index. Sci Rep. 2016;6:31132.

22. Koda M, Murawaki Y, Mitsuda A, Ohyama K, Horie Y, Suou T, Kawasaki H, Ikawa S. Predictive factors for intrahepatic recurrence after percutaneous ethanol injection therapy for small hepatocellular carcinoma. Cancer. 2000; 88(3):529-37.

23. Okuda H, Nakanishi T, Takatsu K, Saito A, Hayashi N, Watanabe K, Magario N, Yokoo T, Naraki T. Measurement of serum levels of des-gamma-carboxy prothrombin in patients with hepatocellular carcinoma by a revised enzyme immunoassay kit with increased sensitivity. Cancer. 1999;85(4):812-8.

24. Nomura F, Ishijima M, Kuwa K, Tanaka N, Nakai T, Ohnishi K. Serum desgamma-carboxy prothrombin levels determined by a new generation of sensitive immunoassays in patients with small-sized hepatocellular carcinoma. Am J Gastroenterol. 1999;94(3):650-4.

25. Taketa K, Endo Y, Sekiya C, Tanikawa K, Koji T, Taga H, Satomura S, Matsuura S, Kawai T, Hirai H. A collaborative study for the evaluation of lectin-reactive alpha-fetoproteins in early detection of hepatocellular carcinoma. Cancer Res. 1993;53(22):5419-23.

26. Katoh H, Nakamura K, Tanaka T, Satomura S, Matsuura S. Automatic and simultaneous analysis of Lens culinaris agglutinin-reactive alpha-fetoprotein ratio and total alpha-fetoprotein concentration. Anal Chem. 1998;70(10):2110-4

27. Yamashita F, Tanaka M, Satomura S, Tanikawa K. Prognostic significance of Lens culinaris agglutinin A-reactive alpha-fetoprotein in small hepatocellular carcinomas. Gastroenterology. 1996;111(4):996-1001.

28. Zhao H, Cai H, Wang C, Huang XF, Cao XX, Zhang L, Zhou DB, Li J. Prognostic value of serum vascular endothelial growth factor and hematological responses in patients with newly-diagnosed POEMS syndrome. Blood Cancer J. 2018;8(4):37.

29. Salazar R, Capdevila J, Laquente B, Manzano JL, Pericay C, Villacampa MM, Lopez C, Losa F, Safont MJ, Gomez A, et al. A randomized phase II study of capecitabine-based chemoradiation with or without bevacizumab in resectable locally advanced rectal cancer: clinical and biological features. BMC Cancer. 2015;15:60.

30. Kato S, Matsumoto M, Matsuyama T, Isonishi A, Hiura H, Fujimura Y. Novel monoclonal antibody-based enzyme immunoassay for determining plasma levels of ADAMTS13 activity. Transfusion. 2006;46(8):1444-52.

31. Matsumoto M, Kawaguchi S, Ishizashi H, Yagi H, lida J, Sakaki T, Fujimura Y. Platelets treated with ticlopidine are less reactive to unusually large von Willebrand factor multimers than are those treated with aspirin under high shear stress. Pathophysiol Haemost Thromb. 2005;34(1):35-40.

32. Kobayashi K, Maruyama H, Kiyono S, Ogasawara S, Suzuki E, Ooka Y, Chiba T, Kato N, Yamaguchi T. Application of transcutaneous ultrasonography for the diagnosis of muscle mass loss in patients with liver cirrhosis. J Gastroenterol. 2018:53(5):652-9.

33. Companioni Napoles O, Tsao AC, Sanz-Anquela JM, Sala N, Bonet C, Pardo ML, Ding L, Simo O, Saqui-Salces M, Blanco VP, et al. SCHLAFEN 5 expression correlates with intestinal metaplasia that progresses to gastric cancer. J Gastroenterol. 2017;52(1):39-49. 
34. Kanda Y. Investigation of the freely available easy-to-use software 'EZR' for medical statistics. Bone Marrow Transplant. 2013;48(3):452-8.

35. Ferracin M, Veronese A, Negrini M. Micromarkers: miRNAs in cancer diagnosis and prognosis. Expert Rev Mol Diagn. 2010;10(3):297-308.

36. Cheung ST, Fan ST, Lee YT, Chow JP, Ng IO, Fong DY, Lo CM. Albumin mRNA in plasma predicts post-transplant recurrence of patients with hepatocellular carcinoma. Transplantation. 2008;85(1):81-7.

37. Ikeda H, Tateishi R, Enooku K, Yoshida H, Nakagawa H, Masuzaki R, Kondo Y, Goto T, Shiina S, Kume Y, et al. Prediction of hepatocellular carcinoma development by plasma ADAMTS13 in chronic hepatitis B and C. Cancer Epidemiol Biomark Prev. 2011;20(10):2204-11.

38. Reuken PA, Kussmann A, Kiehntopf M, Budde U, Stallmach A, Claus RA, Bruns T. Imbalance of von Willebrand factor and its cleaving protease ADAMTS13 during systemic inflammation superimposed on advanced cirrhosis. Liver Int. 2015;35(1):37-45.

39. Tripodi A, Anstee QM, Sogaard KK, Primignani M, Valla DC. Hypercoagulability in cirrhosis: causes and consequences. J Thromb Haemost. 2011;9(9):1713-23.

40. Zhu AX, Duda DG, Sahani DV, Jain RK. HCC and angiogenesis: possible targets and future directions. Nat Rev Clin Oncol. 2011;8(5):292-301.

41. Starke RD, Ferraro F, Paschalaki KE, Dryden NH, McKinnon TA, Sutton RE, Payne EM, Haskard DO, Hughes AD, Cutler DF, et al. Endothelial von Willebrand factor regulates angiogenesis. Blood. 2011;117(3):1071-80.

42. Randi AM. Angiogenesis and the ADAMTS13-WWF balance. Blood. 2017; 130(1):1-2.

43. Liu Y, Wang $X$, Li S, Hu H, Zhang D, Hu P, Yang Y, Ren H. The role of von Willebrand factor as a biomarker of tumor development in hepatitis $\mathrm{B}$ virusassociated human hepatocellular carcinoma: a quantitative proteomic based study. J Proteome. 2014;106:99-112.

44. Takaya H, Kawaratani H, Tsuji Y, Nakanishi K, Saikawa S, Sato S, Sawada Y, Kaji K, Okura Y, Shimozato N, et al. von Willebrand factor is a useful biomarker for liver fibrosis and prediction of hepatocellular carcinoma development in patients with hepatitis B and C. United European Gastroenterol J. 2018;6(9):1401-9.

45. Crawley JT, de Groot R, Xiang Y, Luken BM, Lane DA. Unraveling the scissile bond: how ADAMTS13 recognizes and cleaves von Willebrand factor. Blood. 2011;118(12):3212-21.

46. Koo BH, Oh D, Chung SY, Kim NK, Park S, Jang Y, Chung KH: Deficiency of von Willebrand factor-cleaving protease activity in the plasma of malignant patients. Thromb Res 2002, 105(6):471-476.

47. Nascimbene A, Neelamegham S, Frazier OH, Moake JL, Dong JF. Acquired von Willebrand syndrome associated with left ventricular assist device. Blood. 2016;127(25):3133-41.

48. Edwards DR, Handsley MM, Pennington CJ. The ADAM metalloproteinases. Mol Asp Med. 2008;29(5):258-89.

49. Mochizuki S, Okada Y. ADAM28 as a target for human cancers. Curr Pharm Des. 2009;15(20):2349-58.

50. Mochizuki S, Soejima K, Shimoda M, Abe H, Sasaki A, Okano HJ, Okano H, Okada Y. Effect of ADAM28 on carcinoma cell metastasis by cleavage of von Willebrand factor. J Natl Cancer Inst. 2012;104(12):906-22.

51. Lee M, Keener J, Xiao J, Long Zheng X, Rodgers GM. ADAMTS13 and its variants promote angiogenesis via upregulation of VEGF and VEGFR2. Cell Mol Life Sci. 2015;72(2):349-56.

52. Lee M, Rodansky ES, Smith JK, Rodgers GM. ADAMTS13 promotes angiogenesis and modulates VEGF-induced angiogenesis. Microvasc Res. 2012;84(2):109-15.

53. Park YN, Kim YB, Yang KM, Park C. Increased expression of vascular endothelial growth factor and angiogenesis in the early stage of multistep hepatocarcinogenesis. Arch Pathol Lab Med. 2000;124(7):1061-5.

\section{Publisher's Note}

Springer Nature remains neutral with regard to jurisdictional claims in published maps and institutional affiliations.

Ready to submit your research? Choose BMC and benefit from:

- fast, convenient online submission

- thorough peer review by experienced researchers in your field

- rapid publication on acceptance

- support for research data, including large and complex data types

- gold Open Access which fosters wider collaboration and increased citations

- maximum visibility for your research: over $100 \mathrm{M}$ website views per year

At BMC, research is always in progress.

Learn more biomedcentral.com/submissions 